\title{
AGRESSIVIDADE FISCAL E A LUCRATIVIDADE NAS EMPRESAS DO SETOR DE ENERGIA ELÉTRICA DO BRASIL
}

\author{
TAX AGGRESSIVENESS AND PROFITABILITY IN COMPANIES IN THE \\ ELECTRIC POWER SECTOR IN BRAZIL
}

\author{
DANIEL GOMES DOS SANTOS \\ Universidade Federal do Ceará. Endereço: Av. da Universidade, 2486 | \\ Benfica | 60020-180| Fortaleza/CE | Brasil. \\ Dhttp://orcid.org/0000-0003-2872-9154 \\ daniel.gomes.s@live.com
}

\section{ALAN SANTOS DE OLIVEIRA}

Universidade Federal do Ceará. Endereço: Av. da Universidade, 2486 | Benfica | 60020-180| Fortaleza/CE | Brasil.

(D) http://orcid.org/0000-0002-4947-3517

asoalansantos@gmail.com

\section{RESUMO}

Este estudo teve por objetivo analisar a influência da agressividade fiscal na capacidade de gerar lucro nas empresas do setor de energia elétrica listadas na B3 no período de 2013 a 2018 . Tratase de pesquisa descritiva, quantitativa, documental e bibliográfica. A amostra conta com 37 empresas durante o período estudado, formando um total de 222 observações. Foram utilizadas a BTD (Book Tax Differences) e a GAAP ETR (Generally Accepted Accounting Principles, Effective Tax Rate) como métrica de agressividade fiscal e a ML (Margem Líquida), o ROA (Return on Assets) e o ROI (Return on Investment) como indicadores de lucratividade. Os resultados foram alcançados por meio de estatística descritiva dos dados, análise de regressão linear, na qual foi aplicado um modelo de painel com efeitos aleatórios, e análise de regressão quantílica. Com o resultado detectou-se que, de maneira geral, quanto maior o nível de agressividade fiscal, maiores os índices de lucratividade. Esse estudo visa contribuir para que as empresas do setor de energia elétrica verifiquem a eficiência da utilização de um planejamento tributário agressivo, dando suporte à tomada de decisão.

Palavras-chave: Agressividade Fiscal. Lucratividade. Planejamento Tributário. 


\begin{abstract}
This study aimed to analyze the influence of tax aggressiveness on the ability to generate profit in companies in the electric power sector listed in B3 in the period from 2013 to 2018. This is descriptive, quantitative, documentary and bibliographic research. The sample includes 37 companies during the period studied, forming a total of 222 observations. BTD (Book Tax Differences) and GAAP ETR (Generally Accepted Accounting Principles, Effective Tax Rate) were used as a metric for tax aggressiveness and NM (Net Margin), ROA (Return on Assets) and ROI (Return on Investment) as indicators of profitability. The results were achieved by means of descriptive statistics of the data, linear regression analysis, in which a panel model with random effects was applied, and quantile regression analysis. With the result it was found that, in general, the higher the level of tax aggressiveness, the higher the profitability indexes. This study aims to contribute to companies in the electric power sector to verify the efficiency of the use of aggressive tax planning, supporting decision making.
\end{abstract}

Keywords: Tax Aggressiveness. Profitability. Tax Planning.

\title{
1 INTRODUÇÃO
}

O Brasil foi considerado o segundo país com a maior carga tributária da América Latina em 2016, chegando a representar 32,43\% do Produto Interno Bruto (PIB) em 2017 (Receita Federal do Brasil, 2018). Com a alta incidência de tributos no Brasil, é fundamental que as empresas apostem em um planejamento tributário bem elaborado como forma de reduzir os gastos com tributos e assim maximizar os lucros.

Para Tang (2005), a alta carga tributária prejudica o desempenho das empresas, uma vez que esses encargos afetam negativamente o retorno do investimento e impactam da mesma forma o fluxo de caixa. De maneira complementar, Machado (2011) afirma que o objetivo da gestão fiscal é reduzir o impacto tributário nas organizações através de formas jurídicas, aumentando seu valor de mercado e maximizando seu desempenho.

Schäfer, Konraht e Ferreira (2016) corroboram esse raciocínio afirmando que as empresas do setor de energia elétrica, que distribuíram mais riqueza no período entre 2007 e 2013, possuem menor carga tributária quando comparadas com empresas do setor que geraram menos riqueza. Por outro lado, Ozorio (2015) ressalta que o setor de energia elétrica brasileiro vem passando por mudanças significativas, sendo necessário aumentar a eficiência no uso de seus recursos financeiros.

Shevlin, Edwards e Schwab (2013) e Martinez e Silva (2018) afirmam que o cenário de restrições financeiras está ligado a índices de agressividade fiscais mais elevados, uma vez que as empresas buscam evitar o estado de insolvência através da economia em tributos.

Frente a essa situação, o setor de energia elétrica foi escolhido para esse estudo, considerando as pesquisas de Gupta e Newberry (1997), Tang (2005), Desai e Dharmapala (2006), Chen, Chen, Cheng e Shevlin (2010) e Araújo e Leite Filho (2018), a fim de investigar a relação entre agressividade fiscal e lucratividade e, ainda, com o intuito de reduzir o impacto da disparidade dos índices de lucratividade causado pelo setor de atuação das empresas, visto que naturalmente um ramo de atividade pode ter maior lucratividade que outro (Padoveze \& Benedicto, 2007; Matarazzo, 2010). Além disso, ressalta-se também a influência significativa do setor de energia elétrica no mercado nacional, assim como no desenvolvimento da sociedade (Rosental \& Castro, 2016).

Diante disso, busca-se responder o seguinte questionamento: como a agressividade fiscal pode impactar a lucratividade das empresas do setor de energia elétrica listadas na B3? Assim, esse estudo tem como objetivo analisar a influência da agressividade fiscal na capacidade de gerar lucro nas empresas do setor de energia elétrica listadas na B3 no período de 2013 a 2018, 
de forma a averiguar se um planejamento tributário com maior nível de agressividade pode ser fator diferencial para contribuir com o lucro das empresas do setor elétrico.

O estudo mostra-se relevante dada a importância do tema na atual conjuntura econômica global, na qual a carga tributária pode influenciar diretamente o desempenho das organizações (Tang, 2005; Machado, 2011; Araújo \& Leite Filho, 2018). Por meio desse estudo, investidores e gestores das organizações do setor de energia elétrica podem identificar se a agressividade fiscal está ligada diretamente ao aumento da lucratividade das empresas, de forma a dar suporte na opção de um investimento ou no planejamento tributário adotado.

\section{REFERENCIAL TEÓRICO}

\subsection{Planejamento tributário e agressividade fiscal}

Para Rezende e Nakao (2012), planejamento tributário significa escolher uma alternativa lícita anterior à ocorrência do fato gerador, tendo por objetivo reduzir a carga tributária e aumentar o lucro. Para Martinez (2017), o planejamento tributário visa reduzir as obrigações fiscais, aproveitando as concessões e isenções previstas na legislação tributária, envolvendo a organização operacional da empresa, de forma a diminuir ao mínimo o valor gasto com tributos.

Já agressividade tributária, para Frank, Lynch e Rego (2009) e Chen et al. (2010), é a manipulação do lucro tributável para baixo, sem levar em consideração a licitude do procedimento. De acordo com Martinez (2017), o grau de agressividade tributária mensura o ímpeto em reduzir a incidência de tributos explícitos. Na medida em que aumenta o grau de agressividade, eleva-se também o risco fiscal, especialmente quando o sujeito passivo ultrapassa o limite da elisão fiscal e passa a praticar a evasão fiscal, que consiste em um ato ilegal (Lietz, 2013). Contudo, torna-se difícil perceber o limite da elisão fiscal, uma vez que não há consenso quanto à definição de "evasão fiscal” ou "agressividade fiscal" (Hanlon \& Heitzman, 2010).

\subsection{Medidas de agressividade fiscal}

\subsubsection{Book Tax Difference (BTD)}

BTD é a denominação utilizada para indicar as diferenças entre o lucro contábil e o lucro tributável (Ferreira, Martinez, Costa \& Passamani, 2012). Tais diferenças são geradas pelas distinções entre as normas contábeis e fiscais: essas são elaboradas conforme a legislação fiscal (Hanlon \& Heitzman, 2010), enquanto aquelas são regidas pelos princípios contábeis geralmente aceitos (GAAP's).

Outro motivo que contribui para existência da BTD é o gerenciamento de resultado, que pode ser oriundo do gerenciamento sobre o lucro contábil e/ou de práticas de gerenciamento sobre o lucro tributável (Ferreira et al., 2012). O lucro contábil pode ser manipulado pelos administradores com o propósito de atender ao mercado financeiro, de forma a influenciar a representação fidedigna da situação da empresa (Rezende \& Nakao, 2012). Por outro lado, o gerenciamento de tributos ocorre quando os gestores manipulam as ambiguidades e incertezas legais para beneficiar a empresa (Formigoni, Antunes \& Paulo, 2009).

Para fins de cálculo da BTD, esse estudo utilizará o modelo proposto por Martinez e Passamani (2014), utilizado também por Carvalho (2015) e, posteriormente, por Araújo e Leite Filho (2018), conforme a Equação 1:

$$
\text { BTD Total i, } \mathrm{t}=\frac{\text { LAIR i,t }-(\text { Despesa IRPJ i,t e CSLL i,t } / 0,34}{\text { Ativo Total i,t }}
$$

Em que: BTD Total i,t $=$ BTD Total da empresa i no período $t$

Martinez e Passamani (2014) explicam a metodologia de cálculo exposta, na qual a diferença entre o LAIR (Lucro Anterior ao Imposto de Renda (IRPJ) e Contribuição Social 
(CSLL)) é calculada pelas normas de contabilidade enquanto o cálculo do lucro real é baseado nas normas fiscais. Para chegar à base de cálculo do lucro real, os autores estimam a alíquota de IRPJ e CSLL em 34\%, dos quais $15 \%$ são inerentes ao IRPJ, $10 \%$ são de adicional e IRPJ e aos quais se somam 9\% de CSLL. Por fim, o resultado é normalizado pelo ativo total. Nesse caso, quanto maior o valor da BTD, maior o nível de agressividade fiscal da empresa. É possível obter valores negativos quando o lucro contábil for inferior ao lucro tributável (Hanlon, 2005).

\subsubsection{Generally Accepted Accounting Principles Effective Tax Rate (GAAP ETR)}

Conforme Hanlon e Heitzman (2010) e Dunbar, Higgins, Phillips e Plesko (2010) a ETR é uma proxy utilizada para indicar o grau do planejamento tributário agressivo das empresas. A ETR mensura também a eficácia do planejamento tributário, uma vez que um planejamento eficaz resulta em índice inferior à alíquota nominal dos tributos sobre o lucro (Shackelford \& Shevlin, 2001).

O cálculo da ETR consiste em dividir a Despesa com Imposto de Renda e Contribuição Social pelo Lucro Contábil: quanto maior o resultado, menor o nível de agressividade da empresa. Consequentemente, empresas com menos ETR são mais agressivas tributariamente, uma vez que o valor obtido representará a real taxa tributária incidente (Shackelford \& Shevlin, 2001; Tang, 2005; Hanlon \& Heitzman, 2010, Martinez, 2017).

Hanlon e Heitzman (2010) expõem, a partir das demonstrações contábeis, algumas variações da ETR: GAAP ETR, Cash ETR, Current ETR, LongRun Cash ETR, ETR Differencial. A GAAP ETR, proxy utilizada nesse estudo, é a medida de despesa tributária total por unidade monetária de lucro contábil. Conforme Martinez (2017), as métricas de agressividade relacionadas com a taxa de tributação efetiva são as mais usuais, entre as quais a GAAP ETR é a mais utilizada para indicar o grau de agressividade.

Para calcular a GAAP ETR, conforme Hanlon e Heitzman (2010), utiliza-se a Equação 2:

$$
\text { GAAP ETR }=\frac{\text { Total de Despesa com IRPJ e CSLL }}{\text { Resultado antes do IRPJ e CSLL (LAIR) }}
$$

A exemplo do estudo feito por Araújo e Leite Filho (2018) e Chytis, Tasios e Gerantonis (2018) e Martinez e Silva (2020), nessa pesquisa a ETR é utilizada para mensurar o nível de agressividade fiscal, com o intuito de analisar a relação dessa proxy com a lucratividade das empresas. Contudo, nesse estudo a variação desse indicador é a GAAP ETR.

\subsection{Medidas de lucratividade}

Para este estudo, tomando por base Katz, Khan e Schmidt (2013), Li, Liu e Ni (2017), Araújo e Leite Filho (2018) serão utilizados os índices Margem Líquida (ML), Return on Assets (ROA) e Return on Investment (ROI), como variáveis para mensurar a lucratividade das empresas.

A margem líquida compara o lucro líquido auferido com a receita total de vendas, de forma a evidenciar quanto lucro líquido foi obtido para cada unidade monetária de receita de vendas (Gitman, 2010). Para calcular a ML, conforme Gitman (2010), adota-se a Equação 3:

$$
\mathrm{ML}=\frac{\text { Lucro disponível aos acionistas ordinários }}{\text { Receita de Vendas }}
$$

Segundo Assaf Neto (2012), a Margem Líquida é útil para medir a eficiência global da empresa, uma vez que indica para cada unidade monetária da receita de venda quanto foi utilizado para cobrir os custos e despesas e quanto foi produzido de lucro para a organização.

O ROA é uma medida que calcula o retorno obtido em relação ao investimento em ativos, podendo determinar a tomada de decisão de investimento, já que também possui a função 
de avaliar a eficiência operacional da empresa. É calculada conforme a Equação 4 (Assaf Neto, 2012).

$$
\mathrm{ROA}=\frac{\text { Lucro Gerado pelos Ativos (operacionais) }}{\text { Ativo Total Médio }}
$$

De acordo com Matarazzo (2010) o ROI representa a capacidade de ganho sobre o capital investido, ou seja, quanto maior, melhor. Essa taxa também é utilizada para medir a eficiência global da administração da empresa, visto que avalia a geração de lucro (Kassai, Kassai, Santos \& Assaf Neto, 2000).

Conforme Assaf Neto (2012), a apuração do ROI dá-se segundo a Equação 5:

$$
\text { ROI }=\frac{\text { Lucro Operacional Líquido do IR e CSLL }}{\text { Investimento Médio }}
$$

Em que: Investimento = Ativo Total - Passivo de Funcionamento

Kassai et al. (2000) afirmam que o ROI é a medida mais simples de retorno de investimento, sendo utilizado para avaliar a retribuição dos recursos aplicados, evidenciando a comparação do lucro operacional com o passivo financeiro e o investimento realizado.

\subsection{Relação entre agressividade fiscal e lucratividade}

Conforme Santana (2014), o planejamento tributário visa contribuir para o desempenho econômico-financeiro de uma empresa, maximizando o retorno obtido pelos investidores. Quanto mais agressiva for a empresa, ou seja, quanto maior for seu ímpeto em diminuir a carga tributária em seu planejamento, mais lucros estarão disponíveis para distribuir aos sócios (Hanlon \& Slemrod, 2007; Frank et al., 2009; Machado, 2011).

Katz et al. (2013) investigaram a relação entre agressividade fiscal e rentabilidade atual e futura das empresas. Para isso, utilizaram uma associação entre ROA futuro, margem de lucro operacional líquida, volume de negócios líquido de ativos operacionais atuais e alavancagem do passivo operacional. Foi identificado que em média, apesar de maior retorno antes dos impostos sobre o patrimônio líquido, em relação aos índices associados, as empresas mais agressivas tendem a possuir rentabilidade futura menor em comparação com empresas que não são agressivas tributariamente.

Araújo e Leite Filho (2018) analisaram a relação entre o nível de agressividade fiscal e a rentabilidade das empresas listadas na bolsa de valores brasileira e americana. Utilizaram o ROA como medida da rentabilidade e a BTD e a ETR como medidas de agressividade fiscal. Após análise estatística dos dados foi possível aferir que, em média, o nível de agressividade fiscal influencia negativamente as rentabilidades das empresas.

Não há consenso sobre a influência da agressividade fiscal na lucratividade das empresas. Gupta e Newberry (1997) e Chen et al. (2010) encontraram uma relação positiva entre ETR e ROA, ou seja, quanto melhor o desempenho, maior a carga de tributos. Já estudos realizados por Tang (2005) e Desai e Dharmapala (2006), evidenciam uma relação negativa entre os índices.

Assim, tomando como base as pesquisas de Gupta e Newberry (1997) e Chen et al. (2010), que indicam relação negativa entre a agressividade tributária e desempenho, bem como os estudos de Tang (2005) e Desai e Dharmapala (2006), admitem-se as seguintes hipóteses no estudo:

- $H_{1}$ : O grau de agressividade fiscal impacta no ROA das empresas do setor de energia elétrica listadas na B3.

- $\mathrm{H}_{2}$ : O grau de agressividade fiscal impacta no ROI das empresas do setor de energia elétrica listadas na B3. 
- H3: O grau de agressividade fiscal impacta na ML das empresas do setor de energia elétrica listadas na B3.

\section{METODOLOGIA}

\subsection{Tipologia, população e amostra}

Para desenvolvimento dos procedimentos metodológicos, a pesquisa é classificada como descritiva, quantitativa, documental e bibliográfica.

A população é composta pelas empresas do grupo de utilidades públicas no setor de energia elétrica listadas na B3, totalizando 59 empresas, entre as quais 17 foram excluídas por não possuírem ações sendo comercializadas e 5 empresas por terem sido constituídas para atuar em áreas não ligadas à cadeia produtiva de energia elétrica (trata-se de empresas que atuam como holding), que é composta pelo ramo de geração, comercialização, transmissão e distribuição. No total serão utilizados os dados de 37 empresas do período de 2013 a 2018 , somando 222 observações.

\subsection{Identificação das variáveis e procedimentos de coleta, tratamento e análise dos dados}

Os arquivos para coleta de dados foram extraídos do site da B3, quantificados e tabulados em planilha eletrônica. Após, foram calculados os índices de agressividade (BTD, GAAP ETR) como variáveis independentes, os índices de lucratividade (ML, ROI e ROA) como variáveis dependentes e variáveis de controle (LEV, SIZE e PPE). Em seguida foi utilizada estatística descritiva abrangendo média, mediana, desvio padrão, valor mínimo e máximo para se compreender melhor os dados trabalhados. Para verificar a relação entre os índices de agressividade e lucratividade, foi utilizada regressão linear em painel desbalanceado conforme modelos propostos, bem como regressões quantílicas, visando solucionar problemas com a presença de heterocedasticidade das variáveis.

A Tabela 1 apresenta as variáveis utilizadas na pesquisa que constituem os modelos econométricos a serem apresentados, assim como demonstra a metodologia de cálculo adotada para mensurar as variáveis.

Tabela 1

Variáveis utilizadas na pesquisa

\begin{tabular}{c|c|c|l}
\hline \multicolumn{2}{c|}{ Variáveis } & \multicolumn{1}{c}{ Tipo } & \multicolumn{1}{c}{ Cálculo } \\
\hline \multirow{3}{*}{ Lucratividade } & ROA & Dependente & Lucro Operacional dividido pelo ativo do ano anterior \\
\cline { 2 - 4 } & ROI & Dependente & Lucro Operacional Líquido do IR e CSLL / Investimento Médio \\
\cline { 2 - 4 } & ML & Dependente & Lucro disponível aos acionistas ordinários / Receita de Vendas \\
\hline \multirow{3}{*}{ NAGG } & $\begin{array}{c}\text { GAAP } \\
\text { ETR }\end{array}$ & Independente & $\begin{array}{l}\text { Total de Despesa com IRPJ e CSLL/ Resultado antes do IRPJ e } \\
\text { CSLL }\end{array}$ \\
\cline { 2 - 4 } & BTD & Independente & (Lucro antes do imposto de renda - Lucro real) / Ativo Total \\
\hline $\begin{array}{c}\text { Intensidade } \\
\text { de Capital }\end{array}$ & PIZE & Controle & Logaritmo natural do total de ativos da empresa no início do ano \\
\hline Alavancagem & LEV & Controle & Ativo imobilizado líquido da empresa dividido pelo total de ativo \\
\hline Natano & Controle & Dívida de longo prazo dividida pelo ativo total do ano anterior \\
\hline
\end{tabular}

Nota. ROA = retorno sobre ativos; NAGG = variável que indica nível de agressividade físcal; SIZE = variável que indica o tamanho da empresa; PPE = investimento em ativos (plantas, propriedades e equipamentos); LEV = índice de alavancagem financeira.

Fonte: Elaboração própria (2019)

\subsubsection{Variáveis independentes - Nível de Agressividade Fiscal (NAGG)}

Em se tratando da proxy BTD, considera-se que quanto maior o valor da variável, maior o nível de agressividade fiscal (Martinez \& Dalfior, 2016). Para a ETR, quanto menor o índice, 
maior a agressividade fiscal, visto que representa a taxa efetiva de tributação (Shackelford \& Shevlin, 2001; Tang, 2005; Hanlon \& Heitzman, 2010, Martinez, 2017).

Para eliminar os outliers que distorcem a ETR, adotou-se a metodologia utilizada por Gupta e Newberry (1997) e Araújo e Leite Filho (2018), segundo a qual os valores negativos de ETR assumem valor zero e os valores de ETR superiores a um assumem valor um. Ou seja, nessa pesquisa, os valores referentes à ETR estarão no intervalo [0,1]: o valor de zero sugere ausência de tributação e 1 indica uma taxa efetiva de tributação de $100 \%$.

\subsubsection{Variáveis dependentes - Índices de lucratividade (ML, ROI, ROA)}

Conforme Machado (2011) e Santana (2014), o objetivo do planejamento tributário é maximizar o retorno obtido pelos investidores. Portanto, os índices de lucratividade devem demonstrar também o resultado do conjunto de medidas adotadas para diminuir a carga tributária (Carvalho, 2015). Dessa forma, os índices de lucratividade são comumente utilizados na literatura como um tipo de verificação da eficiência do planejamento tributário (Katz et al., 2013; Araújo \& Leite Filho, 2018).

\subsubsection{Variáveis de controle}

A partir dos estudos realizados por Gupta e Newberry (1997), Richardson e Lanis (2007), Guimarães, Macedo e Cruz (2016), Araújo e Leite Filho (2018) e Martinez e Brito (2019) foram estabelecidas as variáveis SIZE (Tamanho), PPE (Plantas, propriedades e equipamentos) e LEV (Alavancagem).

Reinders e Martinez (2018) indicam que empresas maiores tendem a ser menos agressivas tributariamente, enquanto empresas menores tendem ao oposto. Lopes (2012) justifica que, por causa do maior potencial de dano à sociedade, as autoridades são mais rigorosas ao acompanharem empresas maiores. Portanto, será utilizada a variável SIZE, que é calculada a partir do logaritmo natural do ativo total, de forma equivalente à metodologia adotada nos estudos de Gupta e Newberry (1997), Richardson e Lanis (2007) e Araújo e Leite Filho (2018).

Gupta e Newberry (1997), Richardson e Lanis (2007) e Chen et al. (2010) encontraram evidências de que quanto maior o investimento em ativo imobilizado, menor o montante de impostos pagos. Conforme os autores, pode-se aferir que a relação ocorre devido à possibilidade de dedução da depreciação no cálculo dos tributos e aos incentivos oferecidos por ocasião de grandes investimentos. Para medir o grau de imobilização, Araújo e Leite Filho (2018) utilizaram a variável intensidade de capital (PPE), que corresponde à divisão do ativo imobilizado líquido pelo ativo total (Gupta \& Newberry, 1997; Araújo \& Leite Filho, 2018).

Conforme Frank et al. (2009) e Chen et al. (2010), maiores níveis de alavancagem podem ser reflexo de um planejamento tributário agressivo, objetivando redução da carga líquida de tributos e, consequentemente, níveis mais elevados de agressividade fiscal. Ainda, Gupta e Newberry (1997) afirmam que há relação entre alavancagem e agressividade fiscal, de forma que quanto maior a alavancagem menor a taxa efetiva de tributos incidentes.

Portanto, esse estudo considera a alavancagem como variável de controle, tomando por base os estudos de Gupta e Newberry (1997), Richardson e Lanis (2007), Frank et al. (2009) e Araújo e Leite Filho (2018), nos quais a mensuração da alavancagem se deu em função da dívida de longo prazo dividida pelo ativo total do ano anterior.

\subsection{Apresentação de modelo de regressão linear}

Para atender os objetivos da pesquisa, baseando-se nos estudos de Gupta e Newberry (1997), Richardson e Lanis (2007), Guimarães, Macedo e Cruz (2016) e Araújo e Leite Filho (2018), foram elaborados os modelos de estimações conforme Equações 6, 7 e 8, descritas a seguir: 


$$
\begin{aligned}
\text { MLit } & =\beta 0 \text { it }+\beta 1 \text { NAGGit }+\beta 2 \text { SIZEit }+\beta 3 \text { PPEit }+\beta 4 \text { LEVit }+\varepsilon i t \quad(6) \\
\text { ROIit } & =\beta 0 i t+\beta 1 \text { NAGGit }+\beta 2 \text { SIZEit }+\beta 3 \text { PPEit }+\beta 4 \text { LEVit }+\varepsilon i t \quad(7) \\
\text { ROAit } & =\beta 0 i t+\beta 1 \text { NAGGit }+\beta 2 \text { SIZEit }+\beta 3 \text { PPEit }+\beta 4 \text { LEVit }+\varepsilon i t \quad(8)
\end{aligned}
$$

Além disso, para mensurar o nível de agressividade fiscal (NAGGit) foram utilizadas as proxies BTD e GAAP ETR, de forma que cada modelo econométrico foi testado duas vezes, uma vez para cada variável de agressividade fiscal. Com esse modelo, pretende-se obter como resultado o impacto imediato da agressividade fiscal na lucratividade.

\section{ANÁLISE DOS RESULTADOS}

\subsection{Análise descritiva dos dados}

A Tabela 2 demonstra a estatística descritiva das variáveis adotadas. Para esta tabela foram utilizados dados de 2013 a 2018 de 37 empresas, sendo realizadas, portanto, um total de 222 observações. Ressalta-se que para todas as variáveis tratadas na Tabela 2 foram constatados altos valores de desvio padrão. Isso é atribuído à heterogeneidade já comumente encontrada nos dados contábeis e financeiros (Brito \& Vasconcelos, 2004; Duarte, Girão \& Paulo, 2016).

Tabela 2

Estatística descritiva da amostra, no período de 2013 a 2018

\begin{tabular}{c|c|c|c|c|c|c}
\hline Variáveis & Média & Mediana & Desvio Padrão & Valor Mínimo & Valor Máximo & Observações \\
\hline ML & 0,068866 & 0,068276 & 0,292813 & $-2,279834$ & 0,671417 & 222 \\
\hline ROA & 0,030257 & 0,032889 & 0,075056 & $-0,389008$ & 0,328488 & 222 \\
\hline ROI & 0,070834 & 0,083457 & 0,304309 & $-3,124814$ & 1,159551 & 222 \\
\hline GAAP ETR & 0,246250 & 0,198283 & 0,238625 & 0,000000 & 1,000000 & 222 \\
\hline BTD & 0,077330 & 0,074319 & 0,113578 & $-0,410675$ & 0,498871 & 222 \\
\hline LEV & 0,454653 & 0,435930 & 0,221223 & 0,033087 & 2,295940 & 222 \\
\hline ATIVO & 12456077906 & 7240421000 & 19235558867 & 17463000 & 181210208000 & 222 \\
\hline PPE & 0,542578 & 0,550344 & 0,203667 & $-0,550474$ & 0,952886 & 222 \\
\hline
\end{tabular}

Fonte: Dados da pesquisa (2019)

Conforme a Tabela 2, observa-se nas variáveis de lucratividade uma média de ML no valor de 6,8866\%, percentual que representa a receita bruta que foi convertida em lucro. Já na variável ROA, foi obtido um retorno de 3,0257\% sobre o valor do ativo. Quanto ao ROI, foi obtido um retorno de 0,070834 centavos para cada real investido.

Em se tratando das variáveis de agressividade fiscal, a ETR apresentou carga tributária média de 24,625\%, inferior à alíquota aplicada sobre o lucro das empresas do setor, que é de 34\%. Quanto a BTD, identificou-se uma diferença positiva entre lucro contábil e lucro tributável: para cada real de ativo obtém-se 0,077330 centavos de diferença entre os lucros. $\mathrm{O}$ valor médio positivo da BTD indica que em média as empresas possuem maior lucro contábil do que lucro fiscal, o que, por sua vez, resulta em uma carga tributária inferior.

Quanto às variáveis de controle, foi obtido um valor médio de LEV de 0,454653, e para a PPE, uma média de 0,542578. Já a variável de tamanho, nessa ocasião representada pelo valor do total de ativo, apresentou uma média de aproximadamente 12,456 bilhões.

\subsection{Análise da regressão}

Para a análise foi utilizado modelo de regressão em painel desbalanceado. Devido aos problemas de autocorrelação e heterocedasticidade identificados, foram estimados erros-padrão robustos de Newey-West. Para definir o painel mais indicado para analisar os dados, foram realizados os testes de Chow, Breusch Pagan e Hausman, cujos resultados indicaram que a 
estimação por meio dos efeitos aleatórios era a mais adequada. Ressalta-se que devido à heterocedasticidade das variáveis, as relações de significância se alteram entre os quantis e, portanto, não se deve generalizar os resultados das relações existentes.

\subsubsection{Análise de relação entre NAGG e $M L$}

$\mathrm{Na}$ Tabela 3 foi observado que, em média, há uma significância positiva de $10 \%$ da GAAP ETR $(0,1923)$ na ML, o que indica que quanto maior o nível de agressividade menor a ML. Contudo, essa relação não é confirmada quando examinados os quantis, o que sugere não existir relação de significância quando se observa as empresas de forma segregada em grupos de diferentes níveis de lucratividade.

Em média, foi identificada também uma relação positiva de significância estatística de $1 \%$ da ML com a PPE $(0,4106)$, confirmada em todos os quantis. Portanto, quanto maior o investimento e ativo, maior será a ML. É possível visualizar também relação positiva de $1 \%$ no quantil 25 , negativa de $1 \%$ no quantil 75 e também negativa de $5 \%$ no quantil 50 entre a variável SIZE e a ML, indicando que para empresas com menores ML, quanto maior a empresa, maior a ML. Já para empresas com valores de ML próximos ou acima da média a relação é inversa. As demais variáveis utilizadas nessa pesquisa não apresentaram significância estatística quando relacionadas com a ML.

Tabela 3

Equação de regressão e regressão quantílica da variável ML e variável de interesse GAAP ETR

\begin{tabular}{|c|c|c|c|c|c|}
\hline \multirow{2}{*}{$\begin{array}{c}\text { Variáveis } \\
\text { ML }\end{array}$} & \multirow{2}{*}{$\begin{array}{l}\text { Painel de Efeitos Aleatórios } \\
\text { Robustos }\end{array}$} & & \multicolumn{3}{|c|}{ Regressão Quantílica } \\
\hline & & & Quantil.25 & Quantil.50 & Quantil.75 \\
\hline GAAP ETR & $0,1923 *$ & & 0,0328 & $-0,0091$ & $-0,0336$ \\
\hline LEV & 0,2712 & & 0,0363 & $-0,005$ & 0,0078 \\
\hline SIZE & 0,0021 & & $0,0196 * * *$ & $-0,0119 * *$ & $-0,0328 * * *$ \\
\hline PPE & $0,4106^{* * *}$ & & $0,2782 * * *$ & $0,3464 * * *$ & $0,4515^{* * *}$ \\
\hline Const & $-0,3733$ & & $-0,6115 * * *$ & 0,1655 & $0,6694 * * *$ \\
\hline Teste F & 0,0000 & Pseudo $\mathrm{R}^{2}$ & 0,0661 & 0,0865 & 0,1815 \\
\hline Between $\mathrm{R}^{2}$ & 0,0867 & Obs. & 222 & 222 & 222 \\
\hline Obs. & 222 & & & & \\
\hline
\end{tabular}

Nota. *, ** e *** indicam significância de $10 \%, 5 \%$ e $1 \%$, respectivamente. ** Erros-padrão robustos estimados com correção para autocorrelação e heterocedasticidade por Newey-West.

Fonte: Dados da pesquisa (2019)

Já na Tabela 4 foi observado que, em média, há uma significância positiva de $1 \%$ da BTD $(1,5109)$ na ML. Porém o resultado diverge da relação GAAP ETR e ML conforme a Tabela 3. Além de uma média de nível de significância de $1 \%$, foi identificada uma relação positiva entre agressividade fiscal e ML, indicando que empresas com maior agressividade possuem melhores índices de ML, contrariamente ao resultado anterior. A relação de significância em 1\% entre ML e BTD se repete em todos os quantis. Logo, os resultados divergem de Gupta e Newberry (1997), Richardson e Lanis (2007), Chen et al. (2010) e Araújo e Leite Filho (2018) corroborando Tang (2005) e Desai e Dharmapala (2006).

Em se tratando de alavancagem, foi identificada relação média positiva com significância a $10 \%$, de forma que quanto maior a alavancagem, maior a ML. Contudo, examinando os quantis, apenas os quantis 25 e 50 apresentam significância, ambos de 1\%. Também foi identificada relação inversa com a variável SIZE no quantil 50 e no 75, indicando que quanto maior a empresa, menor a ML. A PPE apresentou relação positiva de significância de $1 \%$ no quantil 75. Nesse quantil, quanto maior o investimento em ativo, maior a ML. As demais variáveis não apresentaram significância estatística. 
Tabela 4

Equação de regressão e regressão quantílica da variável ML e variável de interesse BTD

\begin{tabular}{|c|c|c|c|c|c|}
\hline Variáveis & \multirow{2}{*}{ Painel de Efeitos Aleatórios Robustos } & & \multicolumn{3}{|c|}{ Regressão Quantílica } \\
\hline ML & & & Quantil.25 & Quantil.50 & Quantil.75 \\
\hline BTD & $1,5109 * * *$ & & $1,1788 * * *$ & $1,1754 * * *$ & $1,2110 * * *$ \\
\hline LEV & $0,2444^{*}$ & & $0,1149 * * *$ & $0,0885^{* * *} *$ & 0,0841 \\
\hline SIZE & 0,0106 & & $-0,0049$ & $-0,0093 * * *$ & $-0,0196 * *$ \\
\hline PPE & 0,0806 & & $-0,0098$ & 0,0247 & $0,0708 * * *$ \\
\hline Const & $-0,2281$ & & 0,0012 & 0,1393 & 0,3926 \\
\hline Teste F & 0,0000 & Pseudo $\mathrm{R}^{2}$ & 0,2705 & 0,2919 & 0,3105 \\
\hline Between $\mathrm{R}^{2}$ & 0,6537 & Obs. & 222 & 222 & 222 \\
\hline Obs. & 222 & & & & \\
\hline
\end{tabular}

Nota. *, ** e $* * *$ indicam significância de $10 \%, 5 \%$ e $1 \%$, respectivamente. ** Erros-padrão robustos estimados com correção para autocorrelação e heterocedasticidade por Newey-West.

Fonte: Dados da pesquisa (2019)

A relação entre BTD e ML foi positiva, assim como a relação entre ETR e ML, de forma que a primeira indica que quanto maior a agressividade, maior a ML e a segunda, o oposto. As diferenças entre BTD e ETR também ocorrem em Ramalho e Martinez (2014). Contudo, nesse trabalho, atribui-se a diferença à natureza das proxies utilizadas.

\subsubsection{Análise de relação entre NAGG e ROA}

Na Tabela 5, nota-se, em média, uma correlação positiva de $5 \%$ de significância entre a GAAP ETR $(0,0472)$ e o ROA. Ou seja, as empresas mais agressivas, em média, possuem menor ROA. Essa relação não é confirmada em nenhum quantil, nos quais não é apresentada significância estatística, o que se justifica pela heterogeneidade dos dados contábeis e financeiros. Esse resultado corrobora Araújo e Leite Filho (2018) e Chytis, Tasios e Gerantonis (2018).

A variável SIZE não apresenta significância estatística quando se analisa a média. Contudo, o quantil 25 indica relação positiva de significância de $1 \%$, enquanto o quantil 75 indica relação negativa também com significância de $1 \%$, sugerindo relação positiva ente SIZE e ROA nas empresas menores e relação negativa desses índices nas empresas de maior porte. Nesse caso, a análise quantílica permite afirmar que o resultado obtido no quantil 75 sobre a relação ROA e SIZE corrobora Quirino, Moreira, Melo e Mól (2018), enquanto o quantil 25 os contradizem.

Foi identificada também relação positiva, com significância de 1\%, do ROA com o PPE (0,1788), corroborando Araújo e Leite Filho (2018). A relação com o PPE foi confirmada em todos os quantis, nos quais se obteve o mesmo nível de significância. Isso indica que as empresas, ao aumentarem os investimentos em ativos, elevam também o retorno sobre eles na proporção média de 0,1788 centavos para cada real investido. Além disso, conforme a Tabela 5, não foi possível identificar relação de significância estatística em se tratando da variável de controle LEV. 
Tabela 5

\section{Equação de regressão e regressão quantílica da variável ROA e variável de interesse GAAP} ETR

\begin{tabular}{|c|c|c|c|c|c|}
\hline \multirow{2}{*}{$\frac{\text { Variáveis }}{\text { ROA }}$} & \multirow{2}{*}{$\begin{array}{c}\text { Painel de Efeitos Aleatórios } \\
\text { Robustos }\end{array}$} & & \multicolumn{3}{|c|}{ Regressão Quantílica } \\
\hline & & & Quantil.25 & Quantil.50 & Quantil.75 \\
\hline GAAP ETR & $0,0472 * *$ & & 0,0164 & $-0,0182$ & 0,0102 \\
\hline LEV & 0,0515 & & 0,0101 & 0,0041 & $-0,0189$ \\
\hline SIZE & 0,0027 & & $0,0110 * * *$ & $-0,0000$ & $-0,0080 * * *$ \\
\hline PPE & $0,1788 * * *$ & & $0,1748 * * *$ & $0,1468 * * *$ & $0,1069 * * *$ \\
\hline Const & $-0,1645$ & & $-0,3517 * * *$ & $-0,0395$ & $0,1964 * * *$ \\
\hline Teste F & 0,0000 & Pseudo $\mathrm{R}^{2}$ & 0,1257 & 0,1050 & 0,1290 \\
\hline Between R² & 0,2400 & Obs. & 222 & 222 & 222 \\
\hline
\end{tabular}

Nota. *, ** e *** indicam significância de $10 \%, 5 \%$ e $1 \%$, respectivamente. ** Erros-padrão robustos estimados com correção para autocorrelação e heterocedasticidade por Newey-West.

Fonte: Dados da pesquisa (2019)

A análise da Tabela 6, que trata da relação entre ROA e BTD, contradiz os resultados encontrados na Tabela 5, evidenciando uma relação positiva com significância de $1 \%$ entre ROA e BTD $(0,4374)$. Ou seja, quanto mais agressiva tributariamente for a empresa, maior também o retorno sobre o ativo. $\mathrm{O}$ resultado é confirmado em todos os quantis.

Em média, a relação PPE e ROA não possui significância estatística. Contudo, examinando os quantis é possível identificar relação com significância de $1 \%$ no quantil 25 $(0,0605)$, no quantil $50(0,0256)$ de $5 \%$ e no quantil $75(0,0261)$ de $1 \%$, o que corrobora Araújo e Leite Filho (2018). A relação entre ROA e PPE, na verificação dos quantis, confirma os dados da Tabela 5, indicando que quanto maior o investimento em ativo, maior o retorno sobre eles.

A alavancagem, em média, não apresentou significância estática. Contudo no quantil 75 foi identificada relação positiva de $1 \%$ com o ROA, de forma que quanto maior a alavancagem, maior o retorno sobre o ativo. Já a variável SIZE também não apresentou em média significância estatística. No entanto, no quantil 75 apresentou relação negativa com significância de $1 \%$, de forma que quanto maior a empresa, menor o retorno sobre o ativo imobilizado.

Tabela 6

\section{Equação de regressão e regressão quantílica da variável ROA e variável de interesse BTD}

\begin{tabular}{|c|c|c|c|c|c|}
\hline \multirow{2}{*}{$\frac{\text { Variáveis }}{\text { ROA }}$} & \multirow{2}{*}{$\begin{array}{c}\text { Painel de Efeitos Aleatórios } \\
\text { Robustos } \\
\end{array}$} & & \multicolumn{3}{|c|}{ Regressão Quantílica } \\
\hline & & & Quantil.25 & Quantil.50 & Quantil.75 \\
\hline BTD & $0,4374 * * *$ & & $0,5002 * * *$ & $0,5777 * * *$ & $0,5936 * * *$ \\
\hline LEV & 0,0336 & & 0,0133 & 0,0007 & $0,0252 * * *$ \\
\hline SIZE & $0,0198 * *$ & & 0,0012 & 0,0001 & $-0,0033 * * *$ \\
\hline PPE & 0,0577 & & $0,0605 * * *$ & $0,0256 * *$ & $0,0261 * * *$ \\
\hline Const & $-0,4990 * *$ & & $-0,0864$ & $-0,0265$ & $0,0537 * *$ \\
\hline Teste F & 0,0000 & Pseudo $\mathrm{R}^{2}$ & 0,4593 & 0,5041 & 0,5431 \\
\hline Between $\mathrm{R}^{2}$ & 0,5405 & Obs. & 222 & 222 & 222 \\
\hline Obs. & 222 & & & & \\
\hline
\end{tabular}

Nota. *, ** e *** indicam significância de 10\%, 5\% e 1\%, respectivamente. ** Erros-padrão robustos estimados com correção para autocorrelação e heterocedasticidade por Newey-West.

Fonte: Dados da pesquisa (2019)

Similar ao resultado do comparativo NAGG e ML, a relação entre NAGG e ROA também apresenta contradições que novamente são atribuídas à natureza das proxies de agressividade utilizadas. Contudo, nesse caso a relação positiva entre BTD e ROA é mais significativa (de 1\%) uma vez que a significância da relação entre GAAP ETR e ROA é de 5\% e não se confirma em nenhum dos quantis. Portanto, a relação é considerada mais forte: o impacto 
mostra que quanto mais agressiva a empresa, maior o ROA. Esse resultado assemelha-se com os encontrados por Tang (2005), Desai e Dharmapala (2006) e Castro e Flach (2013).

\subsubsection{Análise de relação entre NAGG e ROI}

Na Tabela 7, em média, não foi constatada nenhuma relação de significância estatística. Contudo, em se tratando da relação GAAP ETR e ROI, foi identificada relação negativa no quantil $50(-0,0840)$ de significância de $5 \%$ e no quantil $75(-0,1356)$ com significância de $1 \%$. O resultado indica que nos quantis 50 e 75 as empresas mais agressivas possuem maior ROI.

Analisando as médias, as variáveis SIZE e PPE não apresentaram significância estatística. Entretanto, a variável SIZE mostrou significância positiva de $5 \%$ no quantil 25 e negativa de $1 \%$ no quantil 75. Já a PPE apresentou significância positiva de $1 \%$ no quantil 25 e negativa também de $1 \%$ no quantil 75 . Esses resultados indicam que quanto maior o SIZE e a PPE no quantil 25, maior o ROI. Já no quantil 75, a relação é inversa: quanto maior o SIZE e a PPE, menor o ROI. A LEV não apresentou significância estatística.

Tabela 7

\section{Equação de regressão e regressão quantílica da variável ROI e variável de interesse GAAP} ETR

\begin{tabular}{cc|ccc}
\hline Variáveis & Painel de Efeitos Aleatórios & \multicolumn{3}{c}{ Regressão Quantílica } \\
\cline { 1 - 4 } ROI & Robustos & Quantil.25 & Quantil.50 & Quantil.75 \\
\cline { 3 - 5 } GAAP ETR & 0,1008 & 0,0005 & $-0,0840^{* *}$ & $-0,1356^{* * *}$ \\
LEV & 0,2045 & 0,0297 & $-0,0477$ & $-0,0645$ \\
SIZE & 0,0092 & $0,0171^{* *}$ & 0,0033 & $-0,0181^{* * *}$ \\
PPE & 0,2844 & $0,2118^{* * *}$ & $-0,0109$ & $-0,2266^{* * *}$ \\
Const & $-0,4101$ & $-0,5043^{* * *}$ & 0,0584 & $0,7542^{* * *}$ \\
\hline Teste F & 0,8391 & 0,0213 & 0,0156 & 0,0489 \\
Between $\mathrm{R}^{2}$ & 0,0016 & Pseudo $\mathrm{R}^{2}$ & 222 & 222 \\
Obs. & 222 & Obs. & & \\
\hline
\end{tabular}

Nota. *, ** e *** indicam significância de $10 \%, 5 \%$ e 1\%, respectivamente. ** Erros-padrão robustos estimados com correção para autocorrelação e heterocedasticidade por Newey-West.

Fonte: Dados da pesquisa (2019)

A Tabela 8, por sua vez, evidencia a relação entre ROI e BTD: nela se observa uma relação positiva de significância estatística de $1 \%$. Essa é confirmada em todos os quantis e sugere que empresas mais agressivas possuem maior ROI e, consequentemente, empresas menos agressivas têm menor ROI.

Nota-se também relação positiva de $1 \%$ de significância estatística em todos os quantis da variável LEV, o que sugere, pela análise quantílica, que quanto maior a alavancagem, maior o ROI. Contudo, essa relação não é confirmada na análise de regressão em painel. A variável SIZE apresentou relação negativa de significância estatística de $10 \%$ no quantil 50 e de $1 \%$ no quantil 75. Também não apresentou significância estatística quando observada a análise de regressão em painel. Já o PPE mostrou relação negativa com significância de $1 \%$ nos quantis 50 e 75 , indicando que quanto maior o investimento em ativos depreciáveis, menor o ROI. Além disso, considerando a análise de regressão em painel, mais uma vez não foi constatada significância estatística. 
Tabela 8

Equação de regressão e regressão quantílica da variável ROI e variável de interesse BTD

\begin{tabular}{|c|c|c|c|c|c|}
\hline Variáveis & \multirow{2}{*}{$\begin{array}{c}\text { Painel de Efeitos Aleatórios } \\
\text { Robustos }\end{array}$} & & \multicolumn{3}{|c|}{ Regressão Quantílica } \\
\hline ROI & & & Quantil.25 & Quantil.50 & Quantil.75 \\
\hline BTD & $1,6787 * * *$ & & $1,1542 * * *$ & $1,2506^{* * *}$ & $1,3693 * * *$ \\
\hline LEV & 0,2530 & & $0,1314 * * *$ & $0,0928 * * *$ & $0,0720 * * *$ \\
\hline SIZE & 0,0002 & & 0,0010 & $-0,0049 *$ & $-0,0096 * * *$ \\
\hline PPE & $-0,1636$ & & $-0,0138$ & $-0,1558 * * *$ & $-0,2517 * * *$ \\
\hline Const & $-0,0913$ & & $-0,1160$ & $0,1468 * *$ & $0,3346 * * *$ \\
\hline Teste F & 0,8391 & Pseudo $\mathrm{R}^{2}$ & 0,3423 & 0,3957 & 0,5431 \\
\hline Between $\mathrm{R}^{2}$ & 0,7350 & Obs. & 222 & 222 & 222 \\
\hline Obs. & 222 & & & & \\
\hline
\end{tabular}

Nota. *, ** e *** indicam significância de 10\%, 5\% e 1\%, respectivamente. ** Erros-padrão robustos estimados com correção para autocorrelação e heterocedasticidade por Newey-West.

Fonte: Dados da pesquisa (2019)

Ao analisar as Tabela 7 e 8, constata-se relação positiva entre agressividade fiscal e ROI. No caso com a variável BTD foi obtida em média relação positiva em todos os quantis. Já a GAAP ETR apresentou forte relação negativa exclusivamente no quantil 75 e relação média negativa no quantil 50, o que corrobora o resultado da relação BTD e ROI. A razão pela qual a GAAP ETR não apresenta significância na média pode ser atribuída à heterogeneidade dos dados contábeis e financeiros, conforme já mencionado. Os resultados encontrados corroboram Tang (2005), Desai e Dharmapala (2006) e Castro e Flach (2013).

A Tabela 9 sintetiza os resultados da análise do Painel de Efeitos Aleatórios Robustos, e a Tabela 10, os resultados da análise de Regressão Quantílica. Ressalta-se a necessidade de observar de forma conjunta a análise quantílica devido à heterocedasticidade das variáveis.

Tabela 9

Síntese dos resultados da análise Painel de Efeitos Aleatórios Robustos

\begin{tabular}{l|c|c|c|c}
\hline Hipótese & $\begin{array}{c}\text { Variável de } \\
\text { Lucratividade }\end{array}$ & $\begin{array}{c}\text { Variável de Agressividade } \\
\text { Fiscal }\end{array}$ & $\begin{array}{c}\text { Relação } \\
\text { encontrada }\end{array}$ & Significância obtida \\
\hline $\mathrm{H}_{1}$ & $\mathrm{ML}$ & GAAP ETR & Negativa & $10 \%$ \\
\hline $\mathrm{H}_{1}$ & $\mathrm{ML}$ & BTD & Positiva & $1 \%$ \\
\hline $\mathrm{H}_{2}$ & $\mathrm{ROA}$ & GAAP ETR & Negativa & $5 \%$ \\
\hline $\mathrm{H}_{2}$ & $\mathrm{ROA}$ & BTD & Positiva & $1 \%$ \\
\hline $\mathrm{H}_{3}$ & ROI & GAAP ETR & Sem significância & Sem significância \\
\hline $\mathrm{H}_{3}$ & ROI & BTD & Positiva & $1 \%$ \\
\hline
\end{tabular}

Fonte: Dados da pesquisa (2019)

Tabela 10

Síntese dos resultados da análise Regressão Quantílica

\begin{tabular}{l|c|c|c|c}
\hline Hipótese & $\begin{array}{c}\text { Variável de } \\
\text { Lucratividade }\end{array}$ & $\begin{array}{c}\text { Variável de Agressividade } \\
\text { Fiscal }\end{array}$ & Relação encontrada & $\begin{array}{c}\text { Significância } \\
\text { obtida }\end{array}$ \\
\hline $\mathrm{H}_{1}$ & $\mathrm{ML}$ & GAAP ETR & Sem significância & Sem significância \\
\hline $\mathrm{H}_{1}$ & $\mathrm{ML}$ & BTD & Positiva & $1 \%$ \\
\hline $\mathrm{H}_{2}$ & ROA & GAAP ETR & Pem significância & Sem significância \\
\hline $\mathrm{H}_{2}$ & ROA & BTD & Positiva nos quantis 50 e 75 & $5 \%$ e $10 \%$ \\
\hline $\mathrm{H}_{3}$ & ROI & GAAP ETR & Positiva & $1 \%$ \\
\hline $\mathrm{H}_{3}$ & ROI & BTD & & $1 \%$ \\
\hline
\end{tabular}

Fonte: Dados da pesquisa (2019)

É possível afirmar que há relação positiva entre lucratividade e agressividade físcal quando utilizada a métrica BTD, uma vez que a relação encontrada no Painel de Efeitos Aleatórios Robustos é confirmada pela análise de Regressão Quantílica. Quando utilizada a métrica GAAP ETR, os resultados da análise do Painel de Efeitos Aleatórios Robustos não são 
confirmados pela análise de Regressão Quantílica. Contudo, em média, é possível identificar relação negativa ao compará-los com a ML e o ROA. Quanto ao ROI, observa-se relação positiva com a agressividade fiscal nos quantis 50 e 75 quando utilizada a proxy GAAP ETR.

\section{CONCLUSÃO}

Essa pesquisa teve como objetivo analisar a influência da agressividade fiscal na lucratividade das empresas do setor de energia elétrica listadas na B3, considerando o período de 2013 a 2018. Ressalta-se que o objetivo foi alcançado após análises descritiva, quantílica e de regressão linear dos dados. Assim, no tocante aos modelos de regressão, para mensurar a agressividade, utilizaram-se as proxies GAAP ETR e BTD e para a lucratividade foram utilizadas as variáveis ML, ROA e ROI e SIZE, LEV e PPE como variáveis de controle. Após analisar os dados, foi possível verificar o impacto significante da agressividade fiscal nos índices de lucratividade estudados.

Analisando os dados da regressão linear, observa-se relação positiva significante entre agressividade fiscal e ML quando utilizada a proxy BTD, e negativa quando utilizada a proxy GAAP ETR. Contudo, a relação negativa obtida pela GAAP ETR não é confirmada nos quantis, o que se justifica pela heterocedasticidade das variáveis. Portanto, confirma-se a $\mathrm{H}_{1}$, haja vista a relação positiva entre BTD e ML, de forma que quanto maior o BTD maior a ML.

Quanto à $\mathrm{H}_{2}$, foi identificada relação forte de significância positiva entre agressividade fiscal e ROA, quando utilizada a BTD como NAGG, de forma que quanto maior a BTD maior o ROA. A análise com a variável GAAP ETR evidenciou, em média, relação negativa entre agressividade e ROA. No entanto, mais uma vez o resultado não é confirmado quando analisados os quantis. Novamente atribui-se o resultado da relação entre GAAP ETR e ROA à heterocedasticidade das variáveis. Portanto, aceita-se $\mathrm{H}_{2} \mathrm{em}$ face da forte relação positiva entre BTD e ROA.

Em se tratando do ROI, observa-se relação positiva com a agressividade fiscal nos quantis 50 e 75 utilizando a variável GAAP ETR. As relações de significância estatística de 5\% encontradas no quantil 50 e de $1 \%$ no quantil 75 indicam que quanto maior a agressividade maior o ROI. Utilizando a proxy BTD o resultado se confirma, em média, em todos os quantis com significância de $1 \%$. Portanto, admite-se relação positiva entre agressividade fiscal e ROI, confirmando também a $\mathrm{H}_{3}$.Conclui-se que, de forma imediata, a agressividade fiscal impacta de forma positiva na lucratividade das empresas do setor de energia elétrica quando utilizada a proxy BTD, ao passo que analisado pela GAAP ETR não foi possível verificar resultado consistente, de maneira que a relação obtida no Painel de Efeitos Aleatórios Robustos não se confirma na Regressão Quantílica. Contudo, em média, foi obtida relação negativa entre agressividade fiscal e ML e ROA. Na Regressão Quantílica houve relação positiva quanto ao ROI apenas nos quantis 50 e 75.

Os resultados assemelham-se aos identificados por Tang (2005), Desai e Dharmapala (2006) e Castro e Flach (2013) e diferem de Gupta e Newberry (1997), Richardson e Lanis (2007), Chen et al. (2010) e Araújo e Leite Filho (2018). Esse estudo contribuiu para que as empresas do setor de energia elétrica possam verificar a eficiência de utilizar um planejamento tributário agressivo, dando suporte à tomada de decisão por parte dos gestores, assim como contribuiu também para a literatura de forma a demonstrar os reflexos da agressividade fiscal na lucratividade das empresas, levando em consideração o setor de atuação.

Esse trabalho limita-se a empresas do setor de energia elétrica relacionadas na B3 que possuíam ações em comercialização e tinham atividades relacionadas diretamente com o setor, no período de estudo entre 2013 e 2018. Portanto, empresas de holding foram excluídas. Há limitações também inerentes às deficiências nas métricas utilizadas, assim como a confidencialidade dos dados tributários. Ressalta-se que o resultado obtido pode sofrer alterações 
caso sejam utilizadas proxies de agressividade fiscal diferentes das utilizadas nessa pesquisa, por exemplo Cash ETR, Current ETR, LongRun Cash ETR.

Sugere-se que pesquisas futuras elaborem estudos direcionados a outros setores da B3, de forma a compreender o comportamento em distintos setores de atuação, além de analisar a relação da agressividade fiscal com outros indicadores de desempenho, bem como outras métricas tributárias.

\section{REFERÊNCIAS}

Araújo, R., \& Leite Filho, P. (2018). Reflexo do nível de agressividade fiscal sobre a rentabilidade de empresas listadas na B3 e NYSE. Revista Universo Contábil, 14(4), 115-136. doi:10.4270/ruc. 2018430

Assaf Neto, A. (2012). Estrutura e análise de balanços: um enfoque econômico-financeiro (10a ed.). São Paulo: Atlas.

Brito, L. A. L., \& Vasconcelos, F. C. de. (2004). A heterogeneidade do desempenho, suas causas e o conceito de vantagem competitiva: proposta de uma métrica. Revista de Administração Contemporânea, 8(spe), 107-129. doi: https://dx.doi.org/10.1590/S1415-65552004000500007

Carvalho, V. G. (2015). Influência das informações tributárias na previsão dos analistas financeiros do mercado de capitais brasileiro. Tese de doutorado em contabilidade, Programa Multi-institucional e Inter-Regional de Pós-Graduação em Ciências Contábeis (UnB/UFPB/UFRN), Natal, Rio Grande do Norte, Brasil.

Castro, J. K., \& Flach, L. (2013). O gerenciamento tributário relacionado ao desempenho das empresas: um estudo nas empresas listadas no nível 1 de governança corporativa da BM\&F BOVESPA. SEMEAD Seminários em Administração, São Paulo, SP, Brasil, 16.

Chen, S., Chen, X., Cheng, Q., \& Shevlin, T. (2010). Are family firms more aggressive than non-family firms? Journal of Financial Economics, 95, 41-61.

Chytis, E., Tasios S., \& Gerantonis N. (2018, junho). Tax avoidance and corporate governance attributes: Evidence from listed companies. 15th International Conference on Enterprise, Systems, Accounting, Logistics and Management, Kefalonia, Greece, 24-26. Recuperado de https://www.researchgate.net/publication/326128323

Desai, M. A., \& Dharmapala, D. (2006). Corporate tax avoidance and High-powered incentives. Jornal of Financial Economics, 79, 145-179.

Duarte, F. C. L., Girão, L. F. A. P., \& Paulo, E. (2017). Avaliando Modelos Lineares de Value Relevance: Eles Captam o que Deveriam Captar? Revista de Administração Contemporânea, 21(spe), 110-134. https://dx.doi.org/10.1590/1982-7849rac2017160202

Dunbar, A., Higgins, D., Phillips, J., \& Plesko, G. (2010). "What Do Measures of Tax Aggressiveness Measure?" Proceedings of the 103rd Annual Conference on Taxation, 18-26. National Tax Association, Washington, DC, USA. 
Ferreira, F. R., Martinez, A. L., Costa, F. M., \& Passamani, R. R. (2012). Book-tax differences e gerenciamento de resultados no mercado de ações do Brasil. Revista de Administração de Empresas, 52(5), 488-501. https://dx.doi.org/10.1590/S0034-75902012000500002

Formigoni, H., Antunes, M. T. P., \& Paulo, E. (2009). Diferença entre o Lucro Contábil e Lucro Tributável: uma análise sobre o Gerenciamento de Resultados Contábeis e Gerenciamento Tributário nas companhias abertas brasileiras. Brazilian Business Review, 6(1), 44-61.

Frank, M. M., Lynch, L. J., \& Rego, S. O. (2009). Tax reporting aggressiveness and its relation to aggressive financial reporting. The Accounting Review, 84(2), 467-496.

Gitman, L. J. (2010). Princípios da administração financeira (12a ed.). São Paulo: Pearson Prentice Hall.

Guimarães, G., Macedo, M. A., \& Cruz, C. (2016). Análise da Alíquota Efetiva de Tributos Sobre o Lucro no Brasil: Um Estudo com foco na ETRt e na ETRc. Enfoque: Reflexão Contábil, 35. doi: https://doi.org/10.4025/enfoque.v35i1.30570

Gupta, S., \& Newberry, K. (1997). Determinants of the variability in corporate effective tax rates: evidence from longitudinal data. Journal of Accounting and Public Policy, 16, 1-34.

Hanlon, M., \& Heitzman, S. (2010). A review of tax research. Journal of Accounting and Economics, 50(2-3), 127-178.

Hanlon, M. (2005). The Persistence and Pricing of Earnings, Accruals, and Cash Flows When Firms Have Large Book-Tax Differences. The Accounting Review, 80. doi: https://doi.org/10.2308/accr.2005.80.1.137

Hanlon, M., \& Slemrod, J. (2007). What does tax aggressiveness signal? Evidence from stock price reactions to news about tax aggressiveness. Journal of Public Economics, 93, 126-141. doi: http://ssrn.com/abstract=975252

Kassai, J. R., Kassai, S., Santos, A., \& Assaf Neto, A. (2000). Retorno de investimento: abordagem matemática e contábil do lucro empresarial (2a ed.). São Paulo: Atlas.

Katz, S., Khan, U., \& Schmidt, A. P. (2013). Tax avoidance and future profitability. Columbia Business School Research Paper. (13-10). doi: http://dx.doi.org/10.2139/ssrn.2227149

Li, O. Z., Liu, H., \& Ni, C. (2017). Controlling Shareholders Incentive and Corporate Tax Avoidance: A Natural Experiment in China. Journal of Business Finance \& Accounting, 44(5-6), 697-727.

Lietz, G. (2013). Tax Avoidance vs. Tax Aggressiveness: A Unifying Conceptual Framework. Working Paper, University of Münster.

Lopes, T. (2012). Custos Políticos Tributários: O Impacto do Tamanho na Alíquota Tributária Efetiva. Tese de doutorado, Universidade de São Paulo, São Paulo, Brasil.

Machado, A. P. (2011). A verdadeira alíquota dos tributos incidentes sobre os lucros das empresas brasileiras. Encontro da associação nacional de pós-graduação em administração ENANPAD, Rio de Janeiro, RJ, Brasil, 35. 
Martinez, A. L. (2017). Agressividade tributária: um survey da literatura. Revista de Educação e Pesquisa em Contabilidade, 11, 106-124. Recuperado em 9 março, 2020, de https://www.redalyc.org/articulo.oa?id=4416/441653809007

Martinez, A. L., \& Brito, F. (2019) Effect of Tax Aggressiveness on CEO Turnover. Recuperado de https://ssrn.com/abstract $=3436078$

Martinez, A. L., \& Dalfior, M. D. (2016). Agressividade fiscal entre companhias controladoras e controladas. Revista da Receita Federal: estudos tributários e aduaneiros, 2(1), 344-362.

Martinez, A. L., \& Passamani, R. R. (2014). Book-Tax Differences e sua Relevância Informacional no Mercado de Capitais no Brasil. Revista de Gestão, Finanças $e$ Contabilidade, 4(2), 20-37.

Martinez, A. L., \& da Silva, R. (2018). Restrição financeira e agressividade fiscal nas empresas brasileiras de capital aberto. Advances in Scientific and Applied Accounting, 11(3), 448-463. doi: 10.14392/asaa.2018110305

Martinez, A. L., \& Silva, R. (2020). Empresas Brasileiras de Capital Aberto que Pagam Menos Impostos Criam Mais Empregos? Revista Catarinense da Ciência Contábil, 19(1), 1-15.

Matarazzo, D. C. (2010). Análise financeira de balanços: abordagem gerencial (7a ed.). São Paulo: Altas.

Ozorio, L. M. (2015). Análise do Desempenho Econômico-Financeiro de Distribuidoras de Energia Elétrica no Brasil. (Texto de discussão n. 66). Rio de Janeiro: UFRJ.

Padoveze, C. L., \& Benedicto, G. C. (2007). Análise das demonstrações financeiras (2a ed.). São Paulo: Thomson Learning.

Quirino, M. C.O., Moreira, C. S., Melo, C. L. L., \& Mól, A. L. R. (2018). Governança Tributária e o Desempenho Financeiro das Empresas Brasileiras. Anais do Congresso USP International Conference in Accounting, São Paulo, SP, 2018, 18.

Ramalho, G. C., \& Martinez, A. L. (2014). Empresas Familiares Brasileiras e a Agressividade Fiscal. Anais do Congresso USP de Controladoria e Contabilidade, São Paulo, SP, Brasil, 14.

Receita Federal do Brasil. (2018). Carga Tributária no Brasil 2017: Análise por tributos e bases de incidência. Brasília, DF: Ministério da Fazenda.

Reinders, A. P. G. S., \& Martinez, A. L. (2018). Qual o Efeito da Agressividade Tributária na Rentabilidade Futura? Uma Análise das Companhias Abertas Brasileiras. Revista de Gestão e Contabilidade da UFPI, 5(1), 3-14.

Rezende, G, P., \& Nakao, S. H. (2012). Gerenciamento de resultados e a relação com o lucro tributável das empresas brasileiras de capital aberto. Revista Universo Contábil, 8(1), 6-21.

Richardson, G., \& Lanis, R. (2007) Determinants of the variability in corporate effective tax rates and tax reform: Evidence from Australia. Journal of Accounting and Public Policy, 26(6), 689-704. 
Rosental, R., \& Castro, N. J. (2016) O Estado e o Setor Elétrico Brasileiro. Jornal dos Economistas, Caderno 326, 4-5, Rio de Janeiro.

Santana, S. L. L. (2014). Planejamento tributário e valor da firma no mercado de capitais brasileiro. Dissertação de Mestrado, Faculdade de Economia, Administração e Contabilidade de Ribeirão Preto, Universidade de São Paulo, Ribeirão Preto, SP, Brasil.

Schäfer, J. D., Konraht, J. M., \& Ferreira, L. F. (2016). O custo tributário nas empresas brasileiras de energia elétrica: uma análise por meio da Demonstração do Valor Adicionado. Revista Capital Científico - Eletrônica, 14(3), 84-99.

Shackelford, D., \& Shevlin, T. (2001). Empirical Tax Research in Accounting. Journal of Accounting and Economics, 31, 321-387.

Shevlin, T., Edwards, A., \& Schwab, C. (2013). Financial constraints and the incentive for tax planning. 2013 American Taxation Association Midyear Meeting: New Faculty/Doctoral Student Session.

Tang, T. Y. H. (2005). Book-Tax Differences, a Proxy for Earnings Management and Tax Management - Empirical Evidence from China. Recuperado em 7 setembro, 2019, de http://ssrn.com/abstract=872389 